Table 1. Considerations For and Against Antimicrobial Stewardship Program (ASP) Involvement in COVID-19 Convalescent Plasma Preauthorization

\begin{tabular}{|c|c|}
\hline For ASP Involvement & Against ASP Involvement \\
\hline $\begin{array}{l}\text { - ASPs already have } \\
\text { preauthorization infrastructure in } \\
\text { place } \\
\text { - Transfusion medicine programs } \\
\text { likely would need to create pre- } \\
\text { authorization processes de novo } \\
\text { and identify how to staff these } \\
\text { - ASP personnel are experts at } \\
\text { creating and applying algorithm- } \\
\text { based preauthorization criteria } \\
\text { - ASPs that are already responsible } \\
\text { for local CovID-19 guidelines can } \\
\text { help contextualize convalescent } \\
\text { plasma use relative to other } \\
\text { potential therapies } \\
\text { - ASP personnel are experts at } \\
\text { cooperative integration with non- } \\
\text { infectious diseases or non- } \\
\text { pharmacy-based service lines }\end{array}$ & $\begin{array}{l}\text { - ASPs have no direct involvement } \\
\text { with transfusion medicine } \\
\text { programs or authority to restrict } \\
\text { access to blood products } \\
\text { - ASP personnel are not experts in } \\
\text { transfusion medicine } \\
\text { - ASP involvement will divert time } \\
\text { away from other important } \\
\text { stewardship activities, such as } \\
\text { antibiotic use monitoring } \\
\text { - ASPs are put in the difficult } \\
\text { position of brokering } \\
\text { convalescent plasma access } \\
\text { against scientific community } \\
\text { recommendations to use only in } \\
\text { the context of randomized, } \\
\text { clinical trials }\end{array}$ \\
\hline
\end{tabular}

\section{References}

1. Dellit TH, Owens RC, McGowan JE, et al. Infectious Diseases Society of America and the Society for Healthcare Epidemiology of America guidelines for developing an institutional program to enhance antimicrobial stewardship. Clin Infect Dis 2007;44:159-177.

2. Stevens MP, Patel PK, Nori P. Involving antimicrobial stewardship programs in COVID-19 response efforts: all hands on deck. Infect Control Hosp Epidemiol 2020;41:744-745.

3. Mazdeyasna $\mathrm{H}$, Nori $\mathrm{P}$, Patel $\mathrm{P}$, et al. Antimicrobial stewardship at the core of COVID-19 response efforts: implications for sustaining and building programs. Curr Infect Dis Rep 2020;22:23.

4. US Food \& Drug Administration website. https://www.fda.gov/media/ 141477/download. Accessed August 25, 2020.

5. Bhimraj A, Morgan RL, Shumaker AH, et al. Infectious Diseases Society of America guidelines on the treatment and management of patients with COVID-19. Infectious Diseases Society of America website. https://www. idsociety.org/practice-guideline/covid-19-guideline-treatment-andmanagement/. Accessed August 25, 2020.

6. FDA news release. Coronavirus (COVID-19) update: FDA revokes emergency use authorization for chloroquine and hydroxychloroquine. US Food \& Drug Administration website. https://www.fda.gov/news-events/ press-announcements/coronavirus-covid-19-update-fda-revokes-emergencyuse-authorization-chloroquine-and. Accessed August 25, 2020.

7. FDA news release. Coronavirus (COVID-19) update: FDA issues emergency use authorization for possible COVID-19 treatment. US Food \& Drug Administration website. https://www.fda.gov/news-events/press announcements/coronavirus-covid-19-update-fda-issues-emergencyuse-authorization-potential-covid-19-treatment. Accessed August 25, 2020

\title{
Regarding data visualization
}

\section{David Birnbaum PhD, MPH (1)}

Applied Epidemiology, Sidney British Columbia, School of Population \& Public Health, University of British Columbia, Vancouver, British Columbia, Canada and School of Health Information Science, University of Victoria, Victoria, British Columbia, Canada

To the Editor-The review by Salinas et $\mathrm{al}^{1}$ introduces many important aspects concerning the science of data visualization. However, the references cited in support of an assertion that the best ways to visualize data remain unclear overlooks several important resources that provide insightful practical advice on optimal choices. In particular, the work of William Cleveland, whose career was devoted to scientific study of visual encoding and decoding of scientific data, and the work of various cognitive psychologists are noteworthy. Cleveland's findings are distilled into 2 very useful books that have been reviewed in this journal. ${ }^{2,3}$ Important findings from cognitive psychology articles are distilled into various comprehensive review publications, like that of Gigerenzer et al. ${ }^{4}$ The graph examples illustrated by Salinas et al should be viewed with key concepts from Cleveland and Gigerenzer in mind. Exploratory data analysis methodology based on data visualization principles and techniques established in the 1970s-1990s “... add an exciting and useful tool to the epidemiologist's repertoire." 5 The works of Cleveland, Gigerenzer, and others were paramount in informing many of the choices I had to make (and defend against those who initially found them unfamiliar) throughout my career in hospital and

Author for correspondence: David Birnbaum, E-mail: david.birnbaum@ubc.ca Cite this article: Birnbaum D. (2021). Regarding data visualization. Infection Control \& Hospital Epidemiology, 42: 1154-1155, https://doi.org/10.1017/ice.2020.457 public health agency projects related to recognizing the onset of adverse trends efficiently and informing a wide range of audiences about comparisons of healthcare-associated infection rates. ${ }^{6-9}$

\section{Acknowledgments.}

Financial support. No financial support was provided relevant to this article.

Conflicts of interest. The author reports no conflicts of interest relevant to this article.

\section{References}

1. Salinas JL, Kritzman J, Kobayashi T, et al. A primer on data visualization in infection prevention and antimicrobial stewardship. Infect Control Hosp Epidemiol 2020;41:948-957.

2. Birnbaum D. Book review, re: Cleveland WS, Visualizing Data. Infect Control Hosp Epidemol 1994;15:763.

3. Birnbaum D. Book review, re: Cleveland WS, The Elements of Graphing Data. Infect Control Hosp Epidemiol 1996;17:706.

4. Gigerenzer G, Gaissmaier W, Kurz-Milcke E, Schwartz LM, Woloshin S. Helping doctors and patients make sense of health statistics. Psychol Sci Public Interest 2007;8:53-96.

5. Shelly MA. Exploratory data analysis: data visualization or torture? Infect Control Hosp Epidemiol 1996;17:605-612.

(C) 2020 by The Society for Healthcare Epidemiology of America. All rights reserved. This is an Open Access article, distributed under the terms of the Creative Commons Attribution licence (http://creativecommons.org/licenses/by/4.0/), which permits unrestricted re-use, distribution, and reproduction in any medium, provided the original work is properly cited. 
6. Birnbaum D, Cummings MJ, Guyton K, Schlotter J, Kushniruk A. Designing public web information systems with quality in mind: public reporting of hospital performance data. Clin Govern Int J 2010;15: 272-278.

7. Hyman DA, Black BS. Public reporting of hospital infection rates: not all change is progress (January 2013). Jurimetrics. Forthcoming, Northwestern Law \& Econ Research Paper No. 12-21, Northwestern University, Institute for Policy Research Working Paper 13-07, Illinois Program in Law, Behavior and Social Science Paper No. LE13-18. Social Science Research Network website. https://ssrn.com/abstract=2219510. Published February 2013. Accessed September 12, 2020.

8. Birnbaum D. Chapter 4, Big data challenges from a public health informatics perspective. In Househ M, Borycki E, Kushniruk A, eds. Big Data, Big Challenges: A Healthcare Perspective. New York: Springer International, 2019.

9. Birnbaum D. Chapter 9, Epidemiologic methods for investigating infections in the healthcare setting. In Jarvis WR, ed. Bennett \& Brachman's Hospital Infections, $7^{\text {th }}$ edition. Philadelphia: Wolters Kluwer; in press.

\title{
Successful public health measures preventing coronavirus disease 2019 (COVID-19) at a Michigan homeless shelter
}

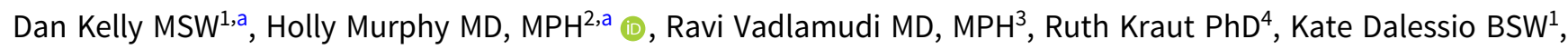 \\ Anurag N. Malani MD², Meghan Glabach ${ }^{2}$ and Juan Luis Marquez MD $^{4}$ \\ ${ }^{1}$ Shelter Association of Washtenaw County, Ann Arbor, Michigan, ${ }^{2}$ St Joseph Mercy Ann Arbor Hospital, Ann Arbor, Michigan, ${ }^{3}$ Packard Health Clinic, Ann Arbor, \\ Michigan and ${ }^{4}$ Washtenaw County Health Department, Michigan
}

To the Editor-Coronavirus disease 2019 (COVID-19) has spread rapidly in homeless shelters across the United States. ${ }^{1,2}$ An investigation in 5 cities identified $37 \%$ and $21 \%$ severe acute respiratory coronavirus virus 2 (SARS-CoV-2) positivity among residents and staff, respectively. ${ }^{3}$ In response, the Centers for Disease Control and Prevention $(\mathrm{CDC})$ urged testing all residents and staff of homeless shelters on April 22. ${ }^{4}$

Delonis Center is the only adult shelter for Washtenaw County (population, 350,000) with 5,000 homeless persons countywide, serving $>1,100$ people annually. Delonis accommodates 60 people per night as a warming shelter and feeds 200 people twice daily. The serviced population is 52\% African American and $45 \%$ Caucasian (average age, 45 years; $70 \%$ male). Notably, 67\% report an underlying disability. More than $70 \%$ have a comorbidity, including heart disease, chronic obstructive pulmonary disease, seizure disorder, and renal failure. Mental health conditions are noted among $48 \%$ and substance abuse among $33 \%$.

Michigan, and particularly southeastern Michigan, was heavily affected by COVID-19 early in the United States, with 65,533 reported cases as of July $5,2020 .{ }^{5}$ Washtenaw County reported 1,067 cases by April 28 (281 per 100,000 population) and 1,526 cases by July $5,2020 .{ }^{5}$ We describe our robust COVID-19 infection prevention strategies at Delonis Center with universal testing results and outcomes.

\section{Methods}

The first case of COVID-19 in Michigan was reported on March 10, 2020- the day the governor declared a state of emergency. We implemented our plan on March 13, including symptom screening (ie, new or worsening cough, dyspnea, subjective or measured fever $\left(\geq 38^{\circ} \mathrm{C}\right.$ or $\left.\left.100.4^{\circ}\right)\right)$ before entry with a riskbased triage, social distancing, and secondary housing at local

Author for correspondence: Holly Murphy, E-mail: holly_murphy@IHAcares.com

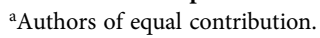

Cite this article: Kelly D, et al. (2021). Successful public health measures preventing coronavirus disease 2019 (COVID-19) at a Michigan homeless shelter. Infection Control \& Hospital Epidemiology, 42: 1155-1156, https://doi.org/10.1017/ice.2020.439 churches or hotels. Clients triaged "green" with negative screen were cleared to sleep at the shelter in regular conditions. Those screened "yellow," with $\geq 1$ symptom, were triaged to mattresses $2 \mathrm{~m}$ (6 feet) apart with surgical masks and underwent a clinical assessment. Those determined ill, or screened "red," were transported to the emergency room. People under investigation were quarantined in private rooms.

We secured a secondary site to enable sheltering in place on March 24, and we secured an offsite hotel on March 29. We implemented a temporary pay increase for staff and recruited 30 extra staff. On April 8, we mandated masks (surgical or cloth). We extended a warming shelter indefinitely to maintain shelter-in-place for all in need. On April 28 and 29, universal screening and molecular testing for SARS-CoV-2 were offered to all residents and staff.

\section{Results}

From March 13 until April 30, 15,000 health screenings were conducted. In total, we sheltered 113 persons (40\%) over age 51 directly at Delonis and 281 persons overall with 4 offsite locations with a nightly average of 135 . On average, 160 individuals (38 at a time, socially distanced) were served a warm meal twice daily. At all sites, clients were encouraged to practice social distancing and to shelter in place. Two positive cases were identified. Both cases were screened "red": the first on March 17 and the second on March 25. On April 28 and 29, molecular testing was performed for 99 residents and 38 staff with 0 positive. As of July 5 , there have been no additional cases.

\section{Discussion}

Our protocol was successful in identifying 2 early symptomatic cases, resulting in zero additional cases once universal testing was implemented.

We attribute the success of our program to key interventions. ${ }^{6}$ Symptom screening before entry, conducted multiple times daily, identified the only 2 COVID- 19 cases at our facility before widespread transmission could occur. Maintaining the warming shelter 